\title{
KOSMOLOGI HINDU DALAM TEKS PURWA BHUMI KAMULAN
}

\author{
I Made Gami Sandi Untara \\ STAH Negeri Mpu Kuturan Singaraja
}

\begin{abstract}
Abstrak
Pengetahuan tentang penciptaan alam semesta atau Kosmologi banyak terdapat dalam karya sastra Jawa Kuna yang sangat penting dikaji agar umat Hindu mengetahui secara mendalam mengenai Kosmologi yang terdapat dalam karya sastra Jawa Kuna. Salah satu karya sastra Jawa Kuna yang mengandung pengetahuan Kosmologi adalah Purwa Bhumi Kamulan. Purwa Bhumi Kamulan termasuk kelompok lontar Tattwa. Lontar ini berisi ajaran tentang penciptan dunia yang diuraikan secara mitologis. Seluruh ajarannya bersifat siwaistik. Proses penciptaan yang diuraikan pada Purwa Bhumi Kamulan dimulai dari Bhatari Uma lahir dari pergelangan kaki Bhatara Guru. Dari kekuatan yoga Bhatara dan Bhatari, lahirlah para Dewata, Panca Rsi, Sapta Rsi sebagai isi dunia ini. Setelah itu barulah dunia ini diciptakan. Pemeliharaan (stithi) dalam teks Purwa Bhumi Kamulan ketika manusia harus senantiasa harus melakukan pemujaaanpemujaaan kepada Bhatara-Bhatari agar terjadinya keseimbangan dalam dunia ini dan peleburan (pralina) dalam teks Purwa Bhumi Kamulan ketika Selain itu Bhatari Durga juga memakan manusia sebagai upah telah menciptakan dunia ini akan tetapi tidak semua manusia yang ada di dunia ini yang dimakan oleh Bhatari Durga. Adapun manusia yang dimakan dengan enaknya oleh Bhatari Durga, tidak lain yang dimakan adalah orang yang lahir pada Wuku Carik, yaitu orang yang lahir pada Wuku Wayang, lahir kembar siam (kadana-kadini), bersaudara lima, tunas tunggul (tunggak wareng), unting-unting.
\end{abstract}

\section{Kata kunci : Kosmologi Hindu, Purwa Bhumi Kamulan}

\section{PENDAHULUAN}

Agama merupakan sebuah keyakinan dasar yang dimiliki oleh setiap umat manusia yang memeluknya. Setiap agama memiliki kitab suci yang dipakai sebagai dasar yang kuat dalam pelaksanaan agamanya, sehingga dengan demikian setiap orang dapat melaksanakan sesuatu yang dianggap baik oleh sebuah agama. Agama Hindu memiliki kitab suci yang disebut dengan Weda yang dapat dijadikan sebagai pedoman dalam kehidupan beragama.

Sebagai kitab suci, Weda adalah sumber ajaran agama Hindu sebab dari Wedalah mengalir ajaran yang merupakan kebenaran agama Hindu. Ajaran Weda dikutip kembali dan memberikan vitalitas terhadap kitab- kitab susastra Hindu pada masa berikutnya. Dari kitab Weda (Sruti) mengalirlah ajarannya dan dikembangkan dalam kitab-kitab Smrti, Ithiasa, Purana, Tantra, Darsana, dan Tatwa-tattwa yang kita warisi di Indonesia (Titib, 1996: 10).

Selain bersumber pada kitabkitab di atas, ajaran agama Hindu juga banyak terkandung atau terdapat di dalam sebuah karya sastra. Di Bali, banyak terdapat sastra-sastra agama yang berupa lontar-lontar berbahasa Sanskerta dan Jawa Kuna yang diterjemahkan ke dalam bahasa Bali dan bahasa Indonesia. Terjemahan ini penting karena untuk menjembatani pembaca yang kurang mampu memahami bahasa Sanskerta dan bahasa 
Jawa Kuna. Aktualisasi hormatnya umat Hindu di Bali dapat dilihat pada tradisi Nyastra. Istilah anak nyastra "orang berilmu" dalam masyarakat Bali, walaupun dalam kenyataannya seorang belum tentu seluas itu penguasaan pengetahuannya. Namun, karena ia senang membaca dan menulis dan dapat berbuat kebaikan/kebajikan terhadap sesama, biasanya orang itu mendapat tempat terhormat di kalangan masyarakat Bali (Bagus, 1980:8).

Sastra Jawa Kuna merupakan salah satu warisan budaya bangsa Indonesia yang mempunyai nilai sangat tinggi. Sejarah telah mencatat bahwa Sastra Jawa Kuna mencapai puncak perkembangannya yang sangat subur atara abad ke-9 hingga abad ke-16 dipusat-pusat kerajaan Hindu, seperti Kerajaan Kediri, Singasari, dan Majapahit (Zoetmulder, 1985:18). Sesuai dengan sistem kekuasaan pada waktu itu hasil Sastra Jawa Kuna umumnya dijiwai oleh agama Hindu. Hasil karya sastra ini tumbuh subur sehingga banyak karya sastra yang lahir, seperti kakawin Bharatayudda, Arjuna Wiwaha, Gatotkacasraya, Siwaratrikalpa, dan sebagainya (Wika, 2013:2).

Oleh karena itu, kepustakaan Bali sangat kaya dan beraneka ragam jenisnya. Keberadaan agama Hindu banyak tersimpan pada kepustakaankepustakaan tersebut, baik mengenai Tattwa, Susila, dan Acara. Naskah keagamaan yang teksnya mengandung ajaran ketuhanan adalah teks Tattwa. Dari sekian banyak teks Tattwa yang ada, ada yang mengandung pengetahuan Kosmologi. Kosmologi merupakan pengetahuan mengenai proses penciptaan alam semesta, menurut Hindu proses penciptaan alam semesta bertumpu pada Tuhan. Tuhan yang dijadikan sebagai penyebab adanya alam semesta ini.

Penelitian mengenai konsep Kosmologi merupakan sebuah penelitian yang sangat menarik untuk dilakukan, 35 hal ini dikarenakan begitu banyak para ilmuwan barat yang membahas mengenai proses penciptaan alam semesta, proses penciptaan alam semesta ini di Barat di kenal dengan istilah Kosmologi sedangkan di timur dikenal dengan istilah Viratvidya. Teori barat dan teori timur sudah pasti memiliki sebuah perbedaan yang sangat mendasar mengenai proses penciptaan alam semesta dan begitu banyak teori barat yang telah digugurkan mengenai proses penciptaan alam semesta ini.

Menurut pandangan Hawking (2004: 34) dinyatakan bahwa di era modern ini banyak teori yang muncul mengenai proses penciptaan alam semesta ini, tetapi walupun dengan peralatan yang begitu canggih yang dimiliki oleh para ilmuwan masalah penciptaan alam semesta ini tidak ada habisnya dibahas, bahkan semakin banyak teori baru yang muncul yang mampu menggugurkan teori sebelumnya. Hal ini disebabkan karena para ilmuwan barat menyimpulkan segala yang ada di dunia ini secara empirisme. Empirisme yang dimaksud adalah berkutat pada data-data yang ada disebuah laboratorium sedangkan para agamawan menyimpulkan tentang proses penciptaan alam semesta ini menggunakan spiritual dan metafisik.

Pengetahuan tentang penciptaan alam semesta atau Kosmologi banyak terdapat dalam karya sastra Jawa Kuna yang sangat penting dikaji agar umat Hindu mengetahui secara mendalam mengenai Kosmologi yang terdapat dalam karya sastra Jawa Kuna. Salah satu karya sastra Jawa Kuna yang mengandung pengetahuan Kosmologi adalah Purwa Bhumi Kamulan.

Purwa Bhumi Kamulan termasuk kelompok lontar Tattwa. Lontar ini berisi ajaran tentang penciptan dunia yang diuraikan secara mitologis. Seluruh ajarannya bersifat siwaistik. Proses penciptaan yang diuraikan pada Purwa Bhumi Kamulan dimulai dari Bhatari Uma lahir dari pergelangan kaki Bhatara 
Guru. Dari kekuatan yoga Bhatara dan Bhatari, lahirlah para Dewata, Panca Rsi, Sapta Rsi sebagai isi dunia ini. Setelah itu barulah dunia ini diciptakan.

\section{PEMBAHASAN}

\subsection{Struktur Penciptaan Dalam Teks Dalam Teks Purwa Bhumi Kamulan}

Donder (2007:110) mengatakan ajaran Hindu selalu melihat sesuatu dimulai dari Tuhan dan berhenti atau berakhir pada Tuhan, karena Tuhan dan ciptaannya juga berbentuk melingkar seperti lingkaran cincin yang tidak dapat diketahui ujung dan pangkalnya. Teks Purwa Bhumi Kawulan dengan sangat jelas dan tegas mengatakan bahwa Bhatara dan Bhatari adalah asal mula segala yang ada, sebagaimana sloka berikut :

Om purwa bhumi kamulan, paduka Bhatari Uma; mijil saking limo-limo nira Bhatara guru. Mulaning hana Bhatari minaka somah Bhatara ; mayoga sira Bhatari. Mijil ta sira dewata, Panca Resi, Sapta Resi; Kosika, sang Garga, Maitri, Kurusya, sang Pratanjala.

\section{(Purwa Bumi Kamulan \#\#)}

Terjemahan:

Om, Purwa Bhumi Kamulan (awal mula dunia). Yang Mulia Bhatari Uma, lahir dari pergelangan kaki Bhatara Guru. Mula-mula yang ada adalah Bhatari, sebagai permaisuri Bhatara. Beryogalah Bhatara dan beryoga pula Bhatari. Lahirlah para dewata, panca resi, sapta resi; Kosika, Sang Garga, Maitri, Kurusya, Sang Pratanjala

ingutus ikang Bhatara, kalih lan sira Bhatari. Kinon sira (ng) gawa loka, neher sira sinanmata, kang wikan patengranira, sina pa de Bhatara. Kosika mlesat mangetan, matemahan dadi dengen, sang
Garga mlesat mangidul, matemahan dadi sang mong. Sang Maitri mlesat mangulon, matemahan dadi ula, Kurusya mlesat mangalor, matemahan dadi bwaya. Pratanjala mlesat (ring) madhya, matemahan hyang kurma raja, ingutus sang Pratanjala, tumurun manggawe loka. Lumampah nda tan parowang, ingutus Bhatari Uma; dening paduka Bhatari, tumurun sang Pratanjala. Neher amit anganjali, Bhatara lawan Bhatari, angadeg sireng pantara, awang-awang uwung-uwung. Tan hananing sarwa katon, tan hana ning sarwa umung. Ahening cipta Bhatari, alekas anggawe loka, maka daging ing bhuwana, kalih lan sang Pratanjala.

(Purwa Bumi Kamulan \#\#)

Terjemahan:

Kemudian Bhatara dan Bhatari disuruh membuat dunia, kemudian ia dinobatkan dan namanya sangat terkenal, dan kemudian di kutuk oleh Bhatara. Kosika pergi ke timur, berubah menjadi dengen. Sang Garga pergi ke selatan , berubah menjadi harimau. Sang Maitri pergi ke barat berubah menjadi ular. Kurusyapergi ke utara berubah menjadi buaya. Pratanjala pergi ke tengah, berubah menjadi kura-kura besar. Sang Pratanjala diutus turun membuat dunia. Berjalan dengan tanpa teman, (karena) diutus oleh Bhatari (Uma), maka turunlah Sang Pratanjala. Lalu menyembah dan mohon diri (ke hadapan) Bhatara dan Bhatari. Berdirilah ia di antara langit yang kosong. Tidak ada sesuatu yang tampak, tidak ada sesuatu yang bersuara. Maka pikiran Bhatari menjadi hening, lalu mengeluarkan mentra-mentra untuk menciptakan dunia, beserta isinya 
dunia, bersama dengan sang Pratanjala.

Dari sloka di atas terlihat jelas bahwa Bhatari merupakan asal mula dari segala sesuatu yang ada di dunia ini baik mahluk yang bernyawa maupun tidak bernyawa. Hal ini dapat dilihat ketika yang pertama kali ada di dunia ini adalah Sang Hyang Bhatara Guru dan Sang Bhatari Uma, lalu dengan Sang Bhatara dan Bhatari beryoga dan lahirlah Para Dewa, Panca Rsi Sapta Resi, Sang Kosika, Sang Garga dan Sang Pratanjala. Lalu kemudian sang Bhatara dan Bhatari membuat isi dunia ini dengan memerintahkan Sang Pratanjala. Sang Pratanjala dengan kekuatannya lalu menyembah dan mohon diri kehadapan Bhatara dan Bhatari. Berdirilah Sang Pratanjala diantara langit yang kosong, tidak ada sesuatu yang tampak, tidak ada sesuatu yang bersuara. Maka pikiran Bhatari menjadi hening dan mengeluarkan mantra-mantra untuk menciptakan dunia beserta isi dunia ini. Setelah dunia ini tercipta lalu Bhatara dan Bhatari menciptakan isi dunia ini seperti Matahari, Bulan, Bintang seperti yang diuraikan dalam teks berikut:

Yoganira sanghyang Dharma mijil tekang maha padma, maka sesek ing bhuwana. Mijil ta radtya wulan, maka suluh ing bhuwana; mijil lintang taranggana, maka tulis ing bhuwana. Mijil panca maha Bhuta, maka urip ing bhuwana; mijil ta catur pramana apah, teja, bayu akasa. Urip ing anda bhuwana sampun apasek; mangke punang jagat traya apan sampun sirayoga.

(Purwa Bumi Kamulan \#\#)

\section{Terjemahan:}

Dari yoga Sanghyang Dharma, keluarlah maha-padma, sebagai pelengkap dunia. Kemudian keluarlah matahari dan bulan sebagai penerang dunia; keluar gugusan bintang-bintang, sebagai hiasan pada dunia. (Kemudian) keluar Panca MahaBhuta, sebagai jiwanya dunia; (kemudian) keluar catur pramana (antara lain) apah, teja, bayu dan akasa. (Sehingga) jiwa anda bhuwana menjadi lengkap dan kuat; dan sekarang ketiga dunia (menjadi sempurna), oleh yoga beliau.

Berdasarkan uraian teks tersebut, setelah Bhatara dan Bhatari menciptakan dunia ini, lalu Bhatara dan Bhatari mulai menghiasi dunia ini dengan melakukan Yoga Semadi. Dan Lahirlah Sang Hyang Darma, dengan kekuatan Sakti Sang Hyang Darma maka terciptanya lah Bintang-bintang, matahari, bulan sebagai penerang di dunia ini, keluarlah Panca Maha Bhuta sebagai jiwa dunia ini, dan yang terahir keluarlah catur pramana sebagai pelengkap dan tenaga yang ada di dunia ini sehingga lengkaplah isi dunia ini.

Berdasarkan pencitaaan (uttpeti) dalam teks Purwa Bhumi Kamulan dijelaskan yang pertama ada didunia ini adalah Bhatara dan Bhatari, lalu Bhatara dan Bhatari menciptakan Para Dewa Dewi, Sapta Rsi, setelah itu Bhatara dan Bhatari dengan kekuatan saktinya menciptakan Alam Semesta ini berserta isinya dimana yang pertama kali diciptakan didunia ini adalah, matahari, bulan, bintang kemudian barulah Bhatara dan Bhatari menciptakan tumbuh-tumbuhan ke dunia ini dilanjutkan menciptakan binatang dan manusia di dunia ini.

\subsection{Struktur Pemeliharaan Dalam Teks Dalam Teks Purwa Bhumi Kamulan}

Mahluk-mahluk hidup yang ada di alam semesta ini terutama manusia selalu menginginkan suatu keadaan hidup yang sejahtera (makmur, sehat dan damai). Dimana kesejahteraan hidup merupakan dambaan bagi semua orang. Dalam hal ini Tuhan menciptakan manusia juga untuk memelihara isi dari alam semesta ini. Karena dengan manusia memelihara alam semesta ini 
maka kesejahteraan hidup manusia akan bisa tercapai.

Selain untuk memelihara dunia ini, Tuhan juga menciptakan manusia dengan tugas masing-masing agar kesejahteraan bisa tercapai. Menurut Untara (2019:54), seorang dari Brahmana warna mengembangkan spritualitas, membangun moral dan mental semua orang. Demikian pula ksatria warna mengusahakan keamanan, ketertiban, keadilan dan kebenaran untuk semua orang. Waisya warna mengusahakan keuntungan financial, baik untuk dirinya maupun untuk orang lain, dan sudra warna pun menyediakan tenaganya untuk menyukseskan swadarma semua pihak. Tentang kesejahteraan itu, di dalam kitab Yajuveda XV.59 disebutkan, "berbuatlah untuk kesejahteraan bersama dan singkirkan kesusahan mereka" Berkaitan dengan kesejahteraan, Bhagavadgîtā menyatakan sebagai berikut:

annād bhavanti bhuūtāni
parjayād anna sambhavah, yajnad bhavati parjanyo yadnah karma samudbhavah.

(Bhagavadgîtā III.14)

Terjemahan:

"Adanya mahluk hidup karena makanan, adanya makanan karena hujan, adanya hujan karena yadnya, adanya yadnya karena karma (Pudja, 1999.87).

Bunyi sloka tersebut juga dapat di tafsirkan bahwa manusia dapat hidup di alam semesta ini karena dengan adanya makanan. Adanya makanan karena alam semesta telah menyediakannya berupa tumbuh-tumbuhan dan binatang yang hidup dengan meminum air yang berasal dari hujan. Dengan adanya alam semesta ini, manusia, binatang dan tumbuhtumbuhan sangat saling membutuhkan dan wajib harus melaksanakan pengorbanan (yajǹa) antar sesama mahluk hidup. Karena dengan mahluk hidup melaksanakan yajǹa di alam semesta ini maka kesejahteraan di alam semesta ini akan terjadi. Kesejahteraan itu dapat di capai juga dengan mahluk hidup yang ada di alam semesta ini selalu berbuat kebaikan dan mengupayakan kedamaian antar sesamanya dan tidak melakukan perbuatan-perbuatan yang menyimpang dari ajaran dharma.

Selain itu kesejahteraan itu dapat terlaksana dengan adanya pelestarian lingkungan hidup. Dalam usaha melestarikan lingkungan adanya konsep Palemahan yaitu hubungan manusia dengan lingkungan (macrocosmos), dimana manusia dengan konsep tersebut menjaga, merawat binatang, tumbuhtumbuhan yang ada di alam semesta ini agar keberadaannya tidak punah. Selain itu, dengan tidak membuang sampah sembarangan, tidak menebang pohon sembarang, tidak melakukan reklamasi pantai juga termasuk salah salu konsep palemahan yang bertujuan untuk pelestarian lingkungan.

Teks Purwa Bumi Kamulan yang merupakan salah satu lontar yang membahas penciptaaan alam semesta ini juga membahas pemeliharaan yang ada di alam semesta ini, sebagaimana yang dijelaskan dalam sloka berikut:

Mangkin krodha Sanghyang Kala, tumurun sira sakareng, angadeg ring sunyantara, anggawe sanggah pamujan. Neher ta ginawe nira, Brahma, Wisnu, Maheswara, tumurun ring madhyapada, arddha moho'nggawe manusa. Hyang Iswara dadi Resi, Hyang Brahma dadi Brahmana, Hyang Wisnu dadi Bhujangga, ya tha sira mangkengutus, dening pada nira Sanghyang, ngaturaken tadah saji, sari genep saji nira, sampun ta mangke winastwan. Dening pada nira Sanghyang, Brahmana, Bhujangga, Resi, Saiwa Kalawan Saugata, anglukata dasa mala. 'Anadah Bhatara Kala, kalih lan Bhatari Durga, tok sekul Kalawan ulan, sarwa genep kang tadahan. Tan ilang takonakena. 
Terjemahan:

\section{(Purwa Bumi Kamulan \#\#)}

Sekarang Sanghyang Kala marah, seketika ia turun, berdiri diantara dunia yang sepi, membuat sanggar pemujaan. Lalu diciptakan Brahma, Wisnu dan Maheswara, kemudian turun kedunia, berkehendak menciptakan manusia. Hyang Iswara menjadi Resi. Hyang Brahma menjadi Brahmana. Hyang Wisnu menjadi Bhujangga. MereKalah kemudian yang diutus oleh Tuhan (Sanghyang), (agar) menghaturkan sajen, segala jenis sajen yang lengkap. Sekarang sudah ditegaskan; oleh Sanghyang, (bahwa) Brahmana, Bhujangga, Resi, Siwa dan Sogata, (boleh) meruwat sepuluh jenis kekotoran.

Berdasarkan uraian dari teks tersebut dijelaskan Sang Hyang Kala marah dan turun ke dunia menciptakan Brahma, Wisnu dan Maheswara kemudian Sang Hyang Kala meminta agar manusia yang ada di dunia ini melakukan pemujaan dan menghaturkan sesajen, sebagaimana yang dijelaskan dalam teks berikut:

Datenge Bhatara Kala, kalih lan Bhatari Durga, angadeg ing puspa-kaki, ingayap ing wado Kala, garjita tumon ing (ta) tadah (an), tan ilang takonakena. Ingundang ing japa mantra, tinabuhan genta-genti, unung kang genta oragan, sangka umung tan pantara. Tutug teka ring akasa, siniratan sekar ura, candana la (wa)n wija kuning, damar murup lawan dhupa. Kukus sakeng dhupa panggi, tutug teka ring akasa, mrebuk arum kang bhuwana, kongas tekeng windu-pada.

(Purwa Bumi Kamulan \#\#)

Terjemahan:

Bersantaplah Bhatara Kala bersama dengan Bhatari Durga, tuak, nasi, dan ikan, berjenis-jenis hidangan lengkap. Dan banyak lagi namanya yang lain. Kemudian Bhatara Kala datang, bersama dengan Bhatari Durga, berdiri diatas tangkai bunga, dipuja oleh para Kala yang merupakan hamba sahayanya, sangat senang hatinya, melihat hidangan. Diundang dengan japamantra, diiringi suara genta yang tiada putus-putusnya, suara genta oragan riuh, suara sangka riuh tidak henti-hentinya. Tembus sampai ke angkasa, ditaburi dengan bunga-bungaan, cendana dan bija berwarna kuning, pedupaan dan dupa menyala. Asap dupa panggil tembus sampai ke angkasa, bumi jadi harum semerbak bahkan sampai ke Windu Pada.

Mulaning hana amuja, kang manuseng madhya-pada, tadahan Bhatara Kala, kalih lan Bhatari Durga. Neher sira siramanya : manusa ring madhya-pada, Purnama Kalawan Tilem, tan kasapa de Hyang Kala, tan kasapa de Hyang Durga, Tan katadah de Hyang Kala, lan katadah de Hyang Durga, pan sampun sinuddha-mala, deni wastu nira Sanghyang.

(Purwa Bumi Kamulan \#\#)

Terjemahan:

(Itulah) awal mulanya adanya manusia dibumi memuja, mempersembahkan sesajen kepada Bhatara Kala, dan kepada Bhatari Durga.Lalu ia berjanji, bahwa setiap Purnama dan Tilem manusia di bumi tidak dikutuk olehBhatara Kala dan tidak pula dikutuk oleh Bhatari Durga. Tidak disantap oleh HyangKala, dan tidak pula dimakan oleh Hyang Durga, sebab sudah disucikan kekotorannya oleh berkat Sanghyang (Tuhan).

Setelah manusia membuat pemujaan dan menghaturkan sesajen berupa tuak, nasi, ikan dan berjenis-jenis hidangan lengkap. Lalu Bhatari Kala dengan Bhatari Durga berdiri diatas tangkai bunga dan dipuja oleh para bhaktanya. Bhatara Kala sangat senang dan menyuruh manusia agar setiap purnama tilem untuk menghaturkan sesajen kepada Bhatara Kala. Jika manusia tidak menghaturkan sesajen makan manusia akan dimakan oleh Sang Hyang Durga.

Berdasarkan konsep pemeliharaan dalam teks Puwa Bumi Kamulan, dalam 
pemeliharaan didunia ini manusia harus senantiasa harus melakukan pemujaaanpemujaaan kepada Bhatara-Bhatari agar terjadinya keseimbangan dalam dunia ini.

Dalam ajaran agama Hindu, tentang keseimbangan itu dapat ditemukan dalam ajaran Tri Hita Karana. Jaman dalam (Nardayana, 2009:188) mengemukakan, istilah Tri Hita Karana berasal dari bahasa sanskerta, yaitu dari kata Tri, Hita dan Karana. Tri berarti tiga; Hita berarti baik, senang, gembira, lestari; Karana berarti penyebab atau sumbernya sebab. Dengan demikian, Tri Hita Karana berarti tiga buah unsur yang merupakan sumbernya sebab yang memungkinkan timbulnya kebaikan. Ajaran Tri Hita Karana ini, juga tertuang dalam kekawin Ramayana yaitu bagaimana Sang Dasaratha berbuat kasih kepada sesama mahluk ciptaan Tuhan, membuat pemujaan terhadap leluhur, dan pemujaan terhadap dewa-dewa. Prilaku hubungan yang selaras, serasi dan seimbang manusia terhadap sesamanya terhadap Tuhannya, terhadap alam semesta beserta isinya akan menjadikan manusia utama. Dengan demikian Tri Hita Karana sebagai perwujudan kesejahteraan dan Kebahagiaan, dimana ketiga unsur yaitu Ida Sang Hyang Widhi Wasa/Tuhan (super natural power), manusia (microcosmos), dan alam semesta/bhuana (macrocosmos) harus saling menjaga.

Hal tersebut telah menjadi pola dasar tatanan kehidupan umat Hindu terutama di Bali, yang dijadikan budaya perilaku sehari-hari, sehingga muncul konsep Tri Hita Karana yang mengajarkan pola hubungan yang harmoni (selaras, serasi dan seimbang) diantara ketiga sumber kesejahteraan dan kebahagiaan tersebut, yang terdiri dari unsur: (1) Parahyangan, harmonis antara manusia dengan Sang Pencipta (Brahman); (2) Pawongan, harmonis antara manusia dengan sesama manusia (microcosmos); (3) Palemahan, harmonis antara manusia dengan bhuana agung (macrocosmos). Berkaitan dengan keseimbangan, menyatakan sebagai berikut:

saha yajnāh prajāh srstvā purovāca prajāpatih,

anema prasavisyadhvam esa vo stv ista käma dhuk.

Terjemahan:

(Bhagavadgîtā III.10)

"Sesungguhnya sejak dahulu dikatakan, Tuhan setelah menciptakan manusia melalui yajña., berkata: dengan (cara) ini engkau akan berkembang, sebagaimana sapi perah yang memenuhi keinginanmu (sendiri)" (Pudja, 1999:84).

Sapi perahan yang dimaksud di sini adalah yang bisa memenuhi segala keinginan yaitu tidak lain adalah bumi, ibu pertiwi ini. Bunyi sloka tersebut memberikan penegasan bahwa cinta kasih seorang ibu terhadap anakanaknya yang tiada terputus ibarat cinta kasih Ibu Pertivi (alam semesta) yang memberikan makanan yang tiada hentihentinya kepada semua mahluk hidup sebagai anak-anaknya sehingga terjadi keseimbangan hidup di antara semua mahluk.

Manusia hidup di alam semesta ini, manusia harus melaksanakan yajǹa. Karena manusia diciptakan oleh Tuhan Yang Maha Esa melalui yajña. Sebagai timbal baliknya, manusia harus melaksanakan yajña. Karena dengan adanya yajnia di alam semesta ini maka keseimbangan hidup di dunia ini akan terjadi.

\subsection{Struktur Peleburan Dalam Teks Dalam Teks Purwa Bhumi Kamulan}

Mahluk hidup yaitu manusia menjadikan dirinya layak untuk mendapatkan keabadian dengan melewati serangkaian kelahiran dan 
kematian berulang kali. Perubahan badan jasmani bukan berarti terjadinya perubahan pada sang roh. Tak satu pun penjelmaan yang tetap tinggal abadi, sebagaimana yang dikatakan sloka berikut:

dehino smim yathā dehe
kaumāram yauvanam jara
tathā dehāntara praptir dhîras
tatra na muhyati

Terjemahan:

(Bhagavadgîtā II.13)

"Sebagaimana halnya dengan sang roh ada pada masa kecil, masa muda dan masa tua demikian juga dengan diperolehnya badan baru, orang bijaksana tak tergoyahkan" (Pudja, 1999:39).

Dari sloka tersebut dijelaskan bahwa setiap mahluk hidup memiliki roh individual, mahluk hidup mengganti badannya setiap saat. Kadang-kadang ia berwujud sebagai anak-anak, kadangkadang sebagai anak remaja, dan kadang sebagai orang yang tua. Namun roh yang sama masih ada dan tidak mengalami perubahan apapun. Akhirnya roh individual tersebut meninggalkan badannya pada waktu meninggal dan berpindah ke badan lain. Oleh karena sang roh pasti akan mendapatkan badan lain dalam penjelmaannya yang akan datang.

Dalam kematian mahluk hidup, tidak ada yang benar-benar musnah. Semuanya adalah perubahan, seperti aliran air yang berganti secara terusmenerus. Atman sebagai Roh Abadi yang berdiam di dalam diri setiap mahluk, tidak mengalami perubahan. Evolusi roh hanyalah sebuah proses lanjutan sebagai jalan pembebasan roh dari belenggu ketidaksadarannya ( $m \bar{a} y \bar{a}$ dan avidy $\bar{a}$ ). Dengan perjalanan secara terus-menerus (reinkarnasi), diharapkan roh akan semakin sadar akan hakikat dirinya yang sejati sehingga bersatu kembali kepada Tuhan (Brahman Atman Aikyam).

Teks Purwa Bumi Kamulan yang merupakan salah satu lontar yang 41 membahas penciptaaan alam semesta ini juga membahas pemeliharaan dan peleburan yang ada di alam semesta ini, sebagaimana yang dijelaskan dalam sloka berikut mengenai halnya peleburan:

Dinelo Bhatari Uma, satampakira Bhatari: hana putih, hana abang, hana kuning, hana ireng. Kaget Bhatari Sri Uma, agila tuwon ing awak, neher masih nadah janma, mangerak masinghanada; waja masalit masiyung, tutukilwir jurang parah ro; netra kadi Surya kembar, irung kadi sumur bandung; kuping Iwir leser ing pa (ha;roma...agimbal;awak awegah aluhur, luhur ira tan pantara; tutug ing anda bhuwana, tutug madhya ning akasa; sira ta Bhatari Durga, aranira duk samana.

(Purwa Bumi Kamulan \#\#)

Terjemahan:

Dipandanglah Bhatari Uma, setiap yang disentuh oleh Bhatari, ada putih, ada merah, ada kuning dan ada yang hitam. Tiba-tiba Bhatari Sri Uma menjadi murka melihat wujud dirinya, lalu tumbuh dorongan untuk memakan manusia, lalu berteriak bagaikan singa meraung. Gigi dan taringnya panjang. Mulutnya bagaikan jurang terbelah dua. Mata bagaikan matahari kembar. Hidung bagaikan sumur kembar. Telinga bagaikan paha berdiri tegak. Rambut digulung, badannya tinggi besar, tingginya tidak terkira, dari anda bhuwana (Bulatan bumi) sampai ke pertengahan langit, beliaulah Bhatari Durga, namanya saat itu.

Dineleng Bhatari Durga, mentas ta saking samudra, sareng lan Bhatara Kala, apa ta jalukanira? Abhasma sira rudhira, kapala ganitri nira, usus ta sandangan-ira, asampet sira bang ireng. Ingemban ingiring-iring, dening wado Kala nira, tan sah ring pasanak ira, angher po sira ring setra. Setra wates pabajangan, kepuh randu kurambiyan, ingayap ing wado Kala, dremba moha nadah janma. Ulih ing anggawe loka, 
tinadah rahina wengi, binuru inguyang uyang, dening wado Kala nira.

\section{(Purwa Bumi Kamulan \#\#)}

Terjemahan:

Dipandangnya Bhatari Durga, lewat samudra, bersama dengan Bhatara Kala. Ia menggunakan darah sebagai basma. Ganitrinya tengkorak manusia. Usus selempangnya. Berselendang berwarna merah dan hitam. Diasuh dan diantar oleh para hambanya (yang terdiri dari) para Kala, tidak jauh dari sanak saudaranya, lalu ia menuju kuburan.Di perbatasan kuburan anak-anak, (pada) pohon kepuh dan randu yang rindang. Dipuja oleh para Kala yang menjadi hambanya, dengan seperti orang mabuk memakan manusia. Upah menciptakan dunia, dimakan., siang dan malam, dikejar dan diperangkap, oleh para Kala yang merupakan para hambanya.

Tinutut sa-paranira, tinadah rahina wengi, kuneng kang tinadah ira, enaknya anadah jalma. Tan salah tinadah-ira, janna wetu wuku carik, wuku wayang wuku nira, kadana (n) lawan kadini. Pandawa lawan metuwang, tunggak wareng, unting-unting, uduh-uduh rare bajang, tinadah rahina wengi.

(Purwa Bumi Kamulan \#\#)

Terjemahan:

Kemana pergi dikejar, dimakan siang dan malam. Adapun manusia yang dimakan dengan enaknya. Tidak lain yang dimakan adalah orang yang lahir pada Wuku Carik, yaitu orang yang lahir pada Wuku Wayang, lahir kembar siam (kadana-kadini), bersaudara lima, tunas tunggul (tunggak wareng), untingunting (?), (itulah yang) dimakan siang dan malam.

Berdasarkan uraian dari teks tersebut dijelaskan bahwa ketika apapun yang disentuh oleh Bhatari Uma akan berubah warna manjadi merah, putih, dan hitam. Tiba-tiba Bhatari Uma menjadi marah dan murka melihat wujud dirinya, lalu berteriak bagaikan singa meraung, gigi dan taringnya panjang, mulutnya bagaikan jurang terbelah dua. Matanya bagaikan matahari kembar, Hidungnya bagaikan sumur kembar, Beliaulah Bhatari Durga, namanya saat itu.

Semua abdi Bhatara Durga dan abdi Bhatara kala melakukan yoga, bulubulunya dijadikan sumber kejahatan, berwujud laki maupun perempuan. Dipandangnya Bhatari Durga, lewat samudra, bersama dengan Bhatara Kala. Lalu Bhatari Durga menggunakan darah sebagai basma. Ganitrinya tengkorak manusia. Usus selempangnya. Berselendang berwarna merah dan hitam. Wujud Bhatari Durga pada saat itu sangat menyeramkan karena Bhatari Durga Dipuja oleh para Kala yang menjadi hambanya. Selain itu Bhatari Durga juga memakan manusia sebagai upah telah menciptakan dunia ini akan tetapi tidak semua manusia yang ada di dunia ini yang dimakan oleh Bhatari Durga. Adapun manusia yang dimakan dengan enaknya oleh Bhatari Durga, tidak lain yang dimakan adalah orang yang lahir pada Wuku Carik, yaitu orang yang lahir pada Wuku Wayang, lahir kembar siam (kadana-kadini), bersaudara lima, tunas tunggul (tunggak wareng), unting-unting.

\section{SIMPULAN}

Berdasarkan uraian di atas maka dapat simpulkan bahwa teks Purwa Bhumi Kamulan termasuk kelompok lontar Tattwa. Lontar ini berisi ajaran tentang penciptaan dunia yang diuraikan secara mitologis. Seluruh ajarannya bersifat Siwaistik. Kosmologi Hindu dalam teks Purwa Bhumi Kamulan terdiri dari penciptaan (uttpeti) dalam teks Purwa Bhumi Kamulan yaitu diuraikan saat Bhatari Uma lahir dari pergelangan kaki Bhatara Guru. Dari kekuatan yoga Bhatara dan Bhatari, lahirlah para Dewata, Panca Rsi, Sapta Rsi sebagai isi dunia ini. Setelah itu barulah dunia ini diciptakan. 
Pemeliharaan (stithi) dalam teks Purwa Bhumi Kamulan ketika manusia harus senantiasa harus melakukan pemujaaanpemujaaan kepada Bhatara-Bhatari agar terjadinya keseimbangan dalam dunia ini dan peleburan (pralina) dalam teks Purwa Bhumi Kamulan ketika Selain itu Bhatari Durga juga memakan manusia sebagai upah telah menciptakan dunia ini akan tetapi tidak semua manusia yang ada di dunia ini yang dimakan oleh Bhatari Durga. Adapun manusia yang dimakan dengan enaknya oleh Bhatari Durga, tidak lain yang dimakan adalah orang yang lahir pada Wuku Carik, yaitu orang yang lahir pada Wuku Wayang, lahir kembar siam (kadana-kadini), bersaudara lima, tunas tunggul (tunggak wareng), unting-unting.

\section{DAFTAR PUSTAKA}

Anonim.tth. Purwa Bhumi Kamulan. Singaraja : Gedong Kirtya.

Bagus, I Gusti Ngurah. 1980. Aksara Dalam Kebudayaan, Suatu Kajian Antropologi. Denpasar: Universitas Udayana.

Donder, I. K. (2007). Kosmologi Hindu:

Penciptaan, Pemeliharaan, dan

Peleburan Serta Penciptaan

Kembali Alam

Semesta. Surabaya: Paramita.

Hawking, Stephen W. 2004. Teori

Segala Sesuatu, Asal Usul dan Kepunahan Alam Semesta. Yogyakarta: Pustaka Belajar.

Nardayana, Wayan. 2009. Kosmologi

Hindu Dalam Kayonan Pada Pertunjukan Wayang Kulit Bali. Tesis. Denpasar: Institut Hindu Dharma Negeri Denpasar.

Titib, I Made. 1996. Veda Sabda Suci (Pedoman Praktis Kehidupan). Surabaya: Paramita.

Untara, I. M. G. S. (2019).

KOSMOLOGI HINDU DALAM
BHAGAVADGĪTĀ. Jñannasiddhâ nta: Jurnal Teologi Hindu, 1(1).

Wika, I Made. 2013. "Kajian Teologi Hindu Kakawin Bharata Yuddha". Tesis. Denpasar: Institut Hindu Dharma Negeri Denpasar.

Wulandari, N. P. A. D., \& Untara, I. M.

G. S. (2020). NILAI-NILAI

FILSAFAT KETUHANAN

DALAM TEKS

ĀDIPARWA. Genta

Hredaya, 4(1). 
Widya Katambung:Jurnal Fisalfat Agama Hindu Vol.11 No.1 2020

Website Jurnal : https://ejournal.iahntp.ac.id/index.php/WK

P-ISSN : 2089-6662

DOI: https://doi.org/ 10.33363/wk.v1 1i1.505 